\title{
TÓXICO E ADICÇÃO COMPARADOS A PAIXÃO E TOXICOMANIA: ETIMOLOGIA E PSICANÁLISE ${ }^{1}$
}

\author{
Victor Eduardo Silva Bento ${ }^{2}$ \\ Universidade Federal do Rio de Janeiro
}

\begin{abstract}
Pela ótica psicanalítica, a etimologia de "tóxico" e "adiç̧ão" foi comparada à "paixão" e "toxicomania", obtendo-se as seguintes conclusões: "tóxico" e "toxicomania" remetem à "substância química" que ataca o organismo; os sentidos etimológicos originários de "paixão" e "tóxico" se assemelham: "paixão como sofrimento passivo frente à ação prejudicial", em Aristóteles e em Cristo, lembra o "tóxico" na ponta das flechas utilizado pelos bárbaros, anteriormente ao século II, nos ataques de guerra, o sofrimento passivo, prejudicial para o atacado; a "toxicomania" se aproxima da paixão, pois nasce no campo médico, no fim do século XIX, definida como "degenerescência", "imoralidade" $e$ "paixão"; o sentido de paradoxo foi encontrado em "tóxico", "toxicomania", e "paixão"; e na "adicção", surgindo no Império Romano como "escravização por determinação legal para pagamento de dívida", reencontrou-se o antigo sentido grego de "paixão como escravização, sofrimento passivo, submissão a uma ação exterior sobre o corpo".
\end{abstract}

Descritores: Tóxico. Adicção. Paixão. Psicanálise. Etimologia.

1 Este artigo foi retirado da tese de doutorado do autor intitulada La Passion Amoureuse "Toxique": Une Approche Psychanalytique à Partir de la Sémiologie et du Narcissisme Chez Freud (Bento, 1996). As citações de obras em francês foram traduzidas para o português pelo autor, quando não foi possível substituí-las por suas correspondentes traduções em edições em português da mesma obra. O presente estudo avança em relação a esta pesquisa, acrescentando novos dados de pesquisa bibliográfica e propondo novas articulações.

2 Doutor em Psicopatologia Fundamental e Psicanálise pela Universidade Paris 7; Docente do Departamento de Psicometria do Instituto de Psicologia da UFRJ. Endereço eletrônico: victorbento@oi.com.br 


\section{Introdução}

Como seu título indica, o objetivo deste trabalho é realizar a etimologia dos termos “tóxico”, prefixo de “tóxico-mania”, 3 e “adicção”, a partir de um ponto de vista psicanalítico. Alguns esclarecimentos caberiam a respeito desta proposta. São eles:

1. Sobre o que se entende por "etimologia” neste trabalho, convém evocar Saussure, sua definição e esclarecimentos sobre este termo. Não sendo "nem uma disciplina distinta, nem uma parte da Lingüística evolutiva”, mas sim, "uma aplicação especial dos princípios relativos aos fatos sincrônicos e diacrônicos", a etimologia "remonta o passado das palavras até encontrar algo que as explique” (Saussure, 1916/1995b, p. 219). A propósito desta função essencialmente explicativa de etimologia, o autor precisa:

A etimologia é, pois, antes de tudo, a explicação das palavras pela pesquisa de suas relações com outras palavras. Explicar quer dizer: reduzir a termos conhecidos, e em Lingüística explicar uma palavra é reduzi-la a outras palavras, (pois) não existem relações necessárias entre o som e o sentido (princípio da arbitrariedade do signo). (...)

3 Não é objetivo deste trabalho estudar a toxicomania. O leitor interessado no estudo específico dos sentidos da "toxicomania”, e não apenas do seu prefixo "tóxico", particularmente no contexto das pesquisas médicas sobre a "toxicomania”, contexto onde nasce a atual noção de "toxicomania", antes mesmo das contribuições de Freud sobre a mesma noção, poderá ser remetido à pesquisa do autor intitulada Pour introduire une "Sémiologie Psychanalytique" de la Notion de "Toxicomanie" dans l'Approche Médicale (Bento, 1999), cuja tradução para o português é: "Para introduzir uma 'Semiologia Psicanalítica' da noção de 'Toxicomania' na abordagem médica". Pequena parte desta pesquisa sobre os sentidos das toxicomanias nestas abordagens médicas, publicada em francês, foi apresentada também no artigo em português de Bento (1998). Já ao leitor interessado no estudo dos sentidos das toxicomanias, e/ou do alcoolismo, e/ou das adicções em geral, no contexto dos escritos de Freud e de outros autores da psicanálise, sugere-se particularmente a leitura das seguintes pesquisas: Bento (1996, item 3.1.2.1); Chassaing, Balbure, Dufour, Farges e Petit (1998); De Mijolla e Shentoub (1973/1981) e Ferbos e Magoudi (1986). 
Tóxico e Adicção Comparados a Paixão e Toxicomania:Etimologia...

A etimologia não se contenta em explicar palavras isoladas; faz a história de famílias de palavras, assim como a faz dos elementos formativos, prefixos, sufixos, etc. (...)

A propósito de uma palavra tomada como objeto de pesquisa, a etimologia toma emprestados seus elementos de (informação) tanto (da) fonética, (quanto da) morfologia, (da) semântica, etc. Para alcançar seus fins, serve-se de todos os meios que a Lingüística lhe põe à disposição, mas não detém sua atenção na natureza das operações que está obrigada a levar a cabo. (p. 220, ver passagem correspondente na edição francesa: Saussure, 1916/1995a, pp. 259-260)

2. Ao se tratar da etimologia de "tóxico" e de "adicção", pretende-se também comparar certos sentidos destes termos com alguns daqueles encontrados nos termos "toxicomania” e "paixão".

\title{
A etimologia do termo "tóxico" e suas relações com a "toxicomania" e a "paixão"
}

No dicionário clássico de língua francesa do século XVIII, Diderot e D’Alembert (1765/1967) definem “toxicum” da seguinte maneira:

\begin{abstract}
Veneno que os Citas e alguns outros povos bárbaros esfregavam na ponta de suas flechas; o toulola dos Índios modernos é talvez o mesmo veneno; o que é certo segundo o testemunho dos historiadores, é que a ferida tocada pelo toxicum dos Citas era mortal; de onde vem que se utilizou a mesma palavra na língua latina, para marcar um veneno contra o qual nada pode impedir o efeito. (p. 501)
\end{abstract}

E "Scythes” (“Citas”) é assim definido pelo Micro-Robert: langue française plus noms propres - chronologie - cartes, um dicionário que, como seu sub-título indica, é especializado em "nomes próprios, cronologia e mapas”: "Os Citas (...) Tribos semi-nômades de origem iraniana vivendo ao norte do mar Negro e que desapareceram no século II. Notáveis cavaleiros e archeiros (aqueles que usavam arco e flecha). Trabalho artístico com ouro e prata” (Robert et al., 1988, p. 255).

O prefixo "tóxico", de "tóxico-mania”, é de fato muito antigo, pois remete à flecha envenenada usada para atacar pelos Citas, povos bárbaros 
que desapareceram no século II, o que sugere a existência do "tóxico" anteriormente mesmo a este século, e, portanto, num momento histórico bem anterior àquele que marca o surgimento da atual noção de "toxicomania”. A respeito desta e de seu aparecimento histórico somente no final do século XIX, Bento (1999) escreve:

Enquanto que o uso de 'drogas’ remonta à Antiguidade, é apenas por volta do final do século XIX que aparece a noção de 'toxicomania', tal como ela é concebida atualmente como associada à imagem de um flagelo social, à idéia de doença e ao domínio médico.

Mais precisamente, esta noção de toxicomania como flagelo social e doença produzida por dependência e por abuso de droga aparece pela primeira vez em 1875 com o alemão Édouard Levinstein, sob o nome de morfiomania. (p. 16)

Um segundo ponto caberia ser destacado como parâmetro de comparação entre "tóxico" e "toxicomania”, desta vez aproximando estes dois termos: embora surgindo em tempos bem distintos, aparecem associados à mesma idéia de uma "substância química" que ataca o organismo.

Finalmente, caberia levantar um terceiro parâmetro para comparar os dois termos, aproximando-os de novo, agora a propósito do sentido passional presente em ambos. Pretende-se, a seguir, apresentar as justificativas desta afirmação. Primeiramente, será demonstrado a existência dos sentidos etimológicos originários do termo "paixão”, implicitamente sugeridos, desde as origens etimológicas do termo "tóxico". Em seguida, se verá que os mesmos sentidos de "paixão" também se encontram presentes nas origens etimológicas do termo “toxicomania”, sendo que, neste último, tratar-se-á de uma presença não implícita, pois a "paixão” será associada claramente, explicitamente, pelos próprios autores médicos, à “toxicomania”.

Como se viu acima, os Citas usavam o "tóxico” para atacar, o que pressupõe a existência simultânea dos sentidos dialéticos opostos de ação (por parte daquele que ataca) e de sofrimento passivo desta ação (por parte daquele que, no lugar da vítima atacada, sofre passivamente a ação de alguém que atua o ataque). Uma tal idéia parece lembrar a origem etimológica do termo "paixão" em seu sentido amplo, isto é, o antigo sentido deste últi- 
Tóxico e Adicção Comparados a Paixão e Toxicomania:Etimologia...

mo termo na Antiguidade grega ${ }^{4}$ também enquanto passividade diante de uma ação. Entre gregos encontrava-se a idéia genérica de paixão enquanto passividade diante do fato de se sofrer uma ação. Mais precisamente, a origem etimológica do termo "paixão" remete a Aristóteles, que distinguia "agir" e "sofrer", no contexto genérico das formas ativas e passivas dos verbos. "Sofrer" (paixão), ou sua forma passiva, indica que o sujeito sofre passivamente a ação expressada pelo verbo, como, por exemplo: o bolo foi devorado pelos convidados. Devido a esta generalidade do termo, existiam diversos tipos de paixão em Aristóteles. A esse respeito, Lalande (1926/1996, p. 781) escreverá:

\section{PAIXÃO (...)}

A. Sentido primitivo (... uma das dez categorias de ARISTÓTELES) (...)

Sobre Paixão - Sentido A. O desaparecimento deste sentido será de lamentar? Seria necessário, na linguagem filosófica, relevar essa acepção ou criar um termo novo para a representar? Dizia-se na primeira redação deste artigo que a antiga oposição entre ação e paixão "representava um modo bastante superficial da descrição dos fatos, tirada sem dúvida por Aristóteles da distinção entre as formas ativas e passivas dos verbos” (TRENDELENBURG, De Aristotelis categoriis, p. 15), distinção à qual já não atribuímos importância lógica, e que não está de acordo com o ponto de vista da física moderna, em que as ações e reações são consideradas como recíprocas. J. Lachelier pensa, pelo contrário, que esta distinção era profunda e importante, e lembra o papel considerável que a oposição entre agir e sofrer desempenha na filosofia e principalmente na teoria do conhecimento, em Espinosa e Leibniz. (Ele) considera que seria bom não perder paixão no sentido antigo e etimológico. (Ver passagem correspondente na edição francesa: Lalande, 1926/1993, p. 745)

Deste verbo em francês "pâtir", em sentido amplo, traduzido para o português como "sofrer”, deriva o "Pathos" da Antiguidade grega, também em sentido amplo. "Pathos”, no dicionário clássico de língua francesa do século XX de nome Le Petit Robert, é um termo oriundo do grego antigo.

4 Não é objetivo deste trabalho discutir os sentidos da “paixão” na Antiguidade grega. Para o leitor interessado em se aprofundar nesta discussão, sugere-se a leitura de Bento (1996, item 2.2). 
Significa: sofrimento, paixão. "Patho", derivado de "Pathos”, significa, segundo o mesmo dicionário: afecção, doença (Robert, 1992, p. 1376). Portanto, em Aristóteles, "Pathos" é sinônimo de "Paixão", ambos os termos, em sentido amplo, significando um sofrimento passivo, também em sentido amplo. Deste "Pathos-Paixão" genérico derivará um "Patho" específico, sinônimo de "Afecção", de "Doença", significando aqui um sofrimento igualmente específico.

Sendo assim, ao lado desse sentido amplo, encontra-se também em Aristóteles um sentido específico do termo "paixão". Neste caso, "paixão", em sentido amplo, como "fato de sofrer passivamente uma ação" se transforma em "fato de sofrer passivamente uma ação prejudicial, dolorosa". Aristóteles (2002) escreverá em "Metafísica” sobre esta "Paixão-Afecção”:

[Os significados de afeç̧ão]

1. Afecção significa, num primeiro sentido, uma qualidade segundo a qual algo pode se alterar: por exemplo, o branco e o preto, o doce e o amargo, o peso e a leveza e todas as outras qualidades deste tipo.

2. Noutro sentido, afecção significa a atuação dessas alterações, isto é, as alterações que estão em ato.

3. Ademais, dizem-se afecções especialmente as alterações e as mudanças danosas e, sobretudo, os danos que produzem dor.

4. Enfim, chamam-se afecções as grandes calamidades e as grandes dores. (p. 247, ver passagem correspondente na edição francesa: Aristote, 1991, p. 208)

Num sentido particular, a "paixão-afecção" se refere às "alterações e aos movimentos prejudiciais e sobretudo aos prejuízos desagradáveis" (Aristote, 1991, p. 208). "Dommage” (prejuízo), segundo Robert (1992, p. 567), é "prejuízo sofrido por alguém”. O mesmo dicionário remete "nuisible" (prejudicial) aos seguintes adjetivos sinônimos: "perigoso, desfavorável, penoso, funesto, daninho, nefasto, nocivo, tóxico” (Robert, 1992, p. 1288, grifo nosso). 
Tóxico e Adicção Comparados a Paixão e Toxicomania:Etimologia...

Este sentido específico de "paixão como fato de sofrer uma ação prejudicial”, em Aristóteles, não estaria ele ainda mais próximo daquele de “tóxico”, acima analisado, como remetendo à idéia de um sofrimento passivo, prejudicial para alguém que é atacado por uma flecha envenenada?

Proximidade maior ainda entre os sentidos etimológicos dos termos paixão e tóxico será encontrada na passagem da Antiguidade grega para o período cristão. ${ }^{5}$ Mais precisamente, como assinala Meyer (1994), na história da paixão, dos sentidos etimológicos originais deste termo entre os gregos, o latim reterá apenas sua acepção específica de sofrimento prejudicial. Apaixonar alguém, doravante, estará, então, associado apenas à idéia de lhe fazer sofrer fisicamente. A noção de paixão passando assim a estar restrita a este único sentido de sofrer um ataque prejudicial, e até mortal, será ligada ao sofrimento de Jesus Cristo, chegando-se mesmo a expressão popular: "a paixão e o sofrimento de Cristo”, sofrimento este que culminará inclusive na sua morte. Este sentido de paixão como sofrimento prejudicial e até mortal não é reencontrado no tóxico enquanto sofrimento produzido pelo ataque de uma flecha envenenada, ataque este mortal, pois era marcado por um veneno contra o qual não se podia impedir o efeito?

Quanto ao termo "toxicomania”, o sentido passional embutido no mesmo em sua origem etimológica é explicitamente mencionado na literatura médica, contexto onde ele nasce. A esse respeito, vale lembrar a pesquisa de Delrieu, que examina mais de quatrocentos textos, estendendo-se sobre quase dois séculos (1800-1960), para construir uma história da moderna “toxicomania” na França. Este autor mostrará que o termo nasce no campo médico, no fim do século XIX, associado aos sentidos de "degenerescência”, “imoralidade” e “paixão”. O autor escreverá a esse respeito:

Considerado como um degenerado, logo como alguém atingido em suas faculdades superiores, particularmente morais, o toxicômano, nestes anos 1871-1898, cai sob o golpe destes tipos de julgamento: é um “viciado”, ou um "perverso”. (...) com

5 Não é objetivo deste trabalho discutir os sentidos da "paixão" no cristianismo. Para o leitor interessado em se aprofundar nesta discussão, sugere-se a leitura de Bento (1996, item 2.3). 
efeito, se é desagradável, para o mundo médico muito afetado por esta paixão, tomar para si tais qualificativos, por outro lado isto agrada àqueles que querem controlar o que alteraria as forças vivas da nação (trabalhadores, soldados, funcionários coloniais). Aqui o ideólogo toma a frente do terapeuta. (Delrieu, 1988, p. 39)

Caberia ainda citar o pai da moderna toxicomania, Édouard Levinstein, em quem se verá o destaque do sentido passional do termo, quando ele escreve sobre o mesmo por meio de sua abordagem da morfiomania: “(...) morfiomania significa a paixão que possui um indivíduo de se servir da morfina como excitante ou como alimento, e o estado patológico que resulta do uso abusivo deste medicamento" (Levinstein, 1878, p. 3).

Voltando ao termo "tóxico", pode-se lembrar que acima foi destacada sua definição no dicionário clássico de língua francesa do século XVIII. Avançando, Littré, no século XIX, fará referência ao mesmo significado originário de "tóxico" como veneno mortal na ponta das flechas, mas também acrescentará uma ampliação semântica ao termo, pois este será associado aos venenos e aos vírus em geral. Este autor escreverá a esse respeito: "Tóxico (...) $1^{\circ}$. Que possui a propriedade de envenenar. Substância química. $2^{\circ}$. S. m. Nome genérico dado aos venenos e aos vírus. $3^{\circ}$. (...) veneno (...), por causa dos venenos que serviam para envenenar as flechas” (Littré, 1967, p. 1161).

No dicionário clássico de língua francesa do século XX, Robert (1992) retomará o mesmo sentido etimológico originário de "tóxico" mencionado nos dicionários de língua francesa dos séculos XVIII e XIX acima destacado. Precisará, assim, que este termo é chamado em latim "toxicum” e em grego "toxikon” (veneno para as flechas, de "toxon”, arco, flecha). Retomará também do dicionário do século XIX o sentido genérico do tóxico, e assim dirá que, enquanto adjetivo, está associado à qualidade genérica de tudo aquilo que age como veneno. Robert escreverá a esse respeito: “Tóxico (...) $1^{\circ}$. Substantivo masculino (Química, Biologia). Veneno. Tóxicos gazosos ou voláteis, minerais, orgânicos. $2^{\circ}$. Adj. (1845). Que age como um veneno. Substância tóxica. Gazes tóxicos” (Robert, 1992, p. 1993).

Vê-se que o sentido etimológico primitivo de tóxico como veneno mortal persiste ao longo do tempo, ainda que a relação social do homem com o 
Tóxico e Adicção Comparados a Paixão e Toxicomania:Etimologia...

veneno tenha se ampliado: estará inicialmente ligada ao ataque de um inimigo de guerra (a flecha envenenada), depois acrescentará o ataque de uma doença (vírus), e, finalmente, significará qualquer ataque por envenenamento.

Além deste sentido de "tóxico como veneno mortal" encontrou-se na literatura dois outros sentidos deste termo. De Félice (1936), por exemplo, estudando os venenos entre os povos primitivos, distinguiu três tipos: 1) Os venenos usados para a caça e para a guerra; 2) Os venenos para provas ou ordálias com fins religiosos e jurídicos; e 3) os venenos místicos.

Os primeiros venenos descritos por De Félice correspondem àquele acima mencionado a propósito da etimologia do termo "tóxico": a ponta da flecha envenenada.

Segundo De Félice, os venenos usados para provas ou ordálias consistiam em submeter pessoas suspeitas de ter cometido alguma falta a uma prova envolvendo um risco de morte. Se sobrevivessem, estaria provada sua inocência; se morressem, seria porque eram culpadas. Acreditava-se que Deus interviria nestas provas, poupando miraculosamente da morte os suspeitos em prova, caso fossem inocentes; ou deixando-os morrer, caso fossem culpados. Embora envolvendo um risco de morte, as provas ordálicas não visavam à morte, mas a sobrevivência miraculosa daqueles que, submetidos às mesmas provas, seriam poupados pelo Senhor. Este, poupando-os por meio de um milagre, revelaria assim sua inocência.

Finalmente, De Félice descreve os venenos místicos, afirmando que os mesmos, da mesma forma como aqueles usados para provas ordálicas, também não visavam à morte. A finalidade aqui era o acesso ao sagrado e ao divino, a produção de estados de êxtases associados à idéia de um deus, com quem os fiéis entravam em comunhão sob o efeito do tóxico. Apoderando-se dos intoxicados, este deus os transportava para fora deles mesmos, fazendo-os, assim, transcender sua existência. De Félice (1936) escreverá a esse respeito:

O primitivo utiliza inicialmente o veneno para tornar suas armas mais mortíferas. Existe igualmente recurso (do veneno) nas cerimônias ao mesmo tempo religiosas e jurídicas, nas quais a finalidade é revelar a culpabilidade ou a inocência das pessoas suspeitas de ter cometido certos crimes. Enfim, ele não hesita em expor-se 


\section{Victor Eduardo Silva Bento}

a perigos que ele não pode ignorar e ele absorve de pleno grado os tóxicos mais temíveis, para degustar desta forma a embriaguez dos êxtases.

Assim, não tanto por sua natureza quanto por sua destinação, os venenos podem ser classificados em três grupos: os venenos de caça e de guerra; os venenos de prova ou ordálias; os venenos místicos. (...)

O tóxico participa no sagrado e no divino, e, em certos casos, ele lhes abre o acesso. Também não devemos nos espantar que ele possa estar cercado, em sua origem mesmo, de um verdadeiro culto, que ritos mais ou menos complicados acompanhem sua preparação e que esta seja freqüentemente confiada a homens especialmente qualificados para uma tal tarefa, seja por seu caráter, seja por sua função.

Dos venenos de caça e de guerra nós só falaremos aqui muito brevemente. Observemos inicialmente que o seu uso remonta aos tempos mais remotos. (...) o homem aprofundava sobre as pontas dos seus dardos, das suas flechas e dos seus arpões sulcos destinados, talvez, a receber substâncias venenosas. (...) a invenção da arma envenenada. (...)

O uso de tóxicos em provas judiciárias ou ordálias é apenas um meio, entre muitos outros, de provocar a intervenção de um agente sobrenatural, considerado infalível, para decidir o valor de certas acusações ou de certas suspeitas. É bem evidente que costumes deste gênero nos introduzem num domínio onde se misturam estreitamente idéias mágicas, religiosas e jurídicas. (pp. 94-97).

É interessante observar que o veneno de prova se tornou em Madagascar uma espécie de divindade, para a qual foi criada uma verdadeira liturgia.

Os malgaxes terminaram então por considerar que a ação do tanguim como marcando a intervenção de um ser sobrenatural, que tomava possessão dos homens e que manifestava sua presença neles, seja matando-os, seja poupando-os. (...) o deus por excelência, com quem os fiéis entram em comunhão e que, se apoderando deles, os transporta invencivelmente para fora deles mesmos. (p. 105)

Caberia destacar que neste sentido paradoxal do termo "tóxico", por um lado, veneno, e, por outro lado e ao mesmo tempo, salvação, sobrevivência miraculosa, transcendência, vê-se uma outra aproximação semântica da "toxicomania”. Para fundamentar esta idéia, pode-se evocar as contribuições de Le Poulichet (1987) que, ao abordar a "toxicomania” de um ponto de vista psicanalítico, proporá o que a autora chama de "Operação do Phár- 
Tóxico e Adicção Comparados a Paixão e Toxicomania:Etimologia...

makon”. E esta operação será caracterizada pelo excesso do "narcisismo auto-erótico", a "uma autoconservação paradoxal”. Para esclarecer estas afirmações tão resumidas e condensadas, pretende-se a seguir analisar as etapas de reflexão pelas quais passou Le Poulichet até chegar à proposição do sentido paradoxal na “Operação do Phármakon”.

A inspiração inicial de Le Poulichet (1987) ao propor a "Operação do Phármakon” é o "Phármakon” platônico descrito por Derrida (1968/1995, 1968/1997), em “A farmácia de Platão”, como sendo, simultaneamente e paradoxalmente, veneno e remédio, droga maléfica e benéfica, filtro de esquecimento e possibilidade de salvação pelo acesso ao lógos. Le Poulichet (1987) abrirá seu livro citando como epígrafe uma passagem de Derrida sobre este "Phármakon" platônico, onde se poderá observar seu sentido paradoxal. Derrida (1968/1997, pp. 73-74) escreverá a esse respeito:

E passa-se então ao diálogo sobre a essência da sabedoria, o melhor phármakon, o remédio capital.

A filosofia opõe, pois, ao seu outro, essa transmutação da droga em remédio, do veneno em contraveneno. Uma tal operação não seria possível se o phármakológos não abrigasse nele mesmo essa cumplicidade dos valores contrários, e se o phármakon em geral não fosse, antes de toda discriminação, o que, dando-se como remédio, pode (se) corromper em veneno, ou o que se dando como veneno pode se verificar remédio, pode aparecer depois de administrado em sua verdade de remédio. A “essência” do phármakon é que, não tendo essência estável, nem caráter “próprio”, não é, em nenhum sentido dessa palavra (metafísico, físico, químico, alquímico), uma substância. O phármakon não tem nenhuma identidade ideal, ele é aneidético, e primeiro porque ele não é monoeidético (no sentido em

6 O “narcisismo auto-erótico” é uma noção freudiana, aliás, bastante polêmica. Não é objetivo deste trabalho discuti-la. O leitor interessado no aprofundamento desta discussão específica poderá encontrá-la em Bento (1994a, e, especialmente, 1996, item 7.1). Para a discussão da noção de narcisismo em geral, da pré-história desta noção na obra de Freud (anteriormente ao seu início histórico oficial com a obra "Sobre o narcisismo: uma introdução" - Freud, 1914/1974), e da construção das noções de "paixões tóxicas” e de "paixão amorosa tóxica”, a partir de Freud, sugerese a leitura de Bento (1993, 1994a, 1994b, 1995, 1996, capítulos 4, 5, 6 e 7, 1998). 
que o Fédon fala do eîdos como de um simples: monoeidés). Esta "medicina” não é um simples. (...)

Esta não-substância farmacêutica não se deixa manejar com toda segurança nem em seu ser, já que ela não o tem, nem em seus efeitos, que podem incessantemente mudar de sentido. Assim, a escritura, anunciada por Theuth como um remédio, como uma droga benéfica, é em seguida devolvida e denunciada pelo rei, depois, no lugar do rei, por Sócrates, como substância maléfica e filtro do esquecimento. Inversamente, e ainda que a legibilidade não seja imediata, a cicuta, essa poção que nunca teve outro nome no Fédon senão o de phármakon, é apresentada a Sócrates como um veneno, mas ela se transforma, pelo efeito do lógos socrático e pela demonstração filosófica do Fédon, em meio de libertação, possibilidade de salvação e virtude catártica. A cicuta tem um efeito ontológico: iniciar à contemplação do eîdos e à imortalidade da alma. Sócrates a toma como tal. (Ver passagem correspondente na edição francesa: Derrida, 1968/1995, pp. 333-335)

Este "Phármakon" platônico, destacado nesta passagem de Derrida como sendo uma "não-substância farmacêutica" paradoxal, ao mesmo tempo veneno e remédio, lembrando, por um lado, o “tóxico” paradoxal em seus sentidos simultâneos de veneno e salvação, não poderia, por outro lado, ser comparado ou assimilado à "paixão", já que esta é igualmente uma "nãosubstância”, e também comporta um sentido paradoxal, como se verá logo abaixo neste mesmo item?

Sobre a “Operação do Phármakon”, Le Poulichet (1987) também a situa mais além da substância química. Em outras palavras, tanto a “Operação do Phármakon" quanto o "Phármakon” platônico evocarão a idéia da existência de uma "não-substância" na base da intoxicação. A respeito desta "Operação do Phármakon”, mais além da droga, Le Poulichet (1987) escreverá:

Eu tentarei num primeiro tempo especificar as qualidades desta operação, afastando-me dos modelos psicofarmacológicos. É apenas após ter apreciado as características desta operação do phármakon - que não é equivalente ao uso de drogas - que eu examinarei o tipo de formação ao qual ela pertence. Apenas neste momento eu abordarei o lugar desta formação nas diferentes toxicomanias. (p. 39).

Pode-se já pressentir que o verdadeiro tóxico - aquele que nos ocupa numa clínica psicanalítica - não é provavelmente a droga em si! (p. 73) 
Tóxico e Adicção Comparados a Paixão e Toxicomania:Etimologia...

Para precisar o que seria esta não-substância, mais além da droga, na base da intoxicação, ou mais precisamente, da "Operação do Phármakon”, Le Poulichet não a comparará com a "paixão", conforme foi questionado acima. No entanto, ao criticar as teorias de inspiração psicanalítica sobre as toxicomanias influenciadas pelo modelo positivista de ciência, conduzirá o leitor à compreensão de que tais teorias têm valorizado o exterior, o que é objetivamente observável: a substância química e o comportamento de se auto-administrar tal substância, esquecendo-se, assim, do interior, do inconsciente, de refletir o que seria a intoxicação de um ponto de vista verdadeiramente psicanalítico, valorizando o subjetivo. É neste momento que a autora evocará a figura plural da “paixão”, presente nas primeiras definições médicas na origem das modernas toxicomanias do final do século XIX, deplorando o esquecimento desta imagem por parte das atuais abordagens psicanalíticas das toxicomanias. Le Poulichet escreverá a esse respeito:

... Precisamente, uma certa psicanálise pode validar esta dupla empreitada de medicalização e psicologização das toxicomanias. A figura plural da 'paixão', que dominava no século XIX para dar conta das toxicomanias e que não separava o corpo da 'alma', teria constituído uma base mais propícia à reflexão psicanalítica, conservando a dimensão subjetiva e enigmática da experiência. (p. 13)

Foi com a finalidade de trazer uma teorização rigorosa em psicanálise das toxicomanias, que a autora propôs a “Operação do Phármakon”. Esta operação investiria também numa "não-substância” que, como já foi assinado, Le Poulichet não refere como sendo a paixão, mas sim, o excesso do "narcisismo auto-erótico", um investimento que remeteria a uma autoconservação paradoxal. Até chegar a uma tal proposição a autora passará pelas etapas lógicas apresentadas a seguir.

Primeiramente, Le Poulichet afirmará que tanto a toxicomania que investe nas substâncias químicas quanto a "Operação do Phármakon” em torno da "não-substância”, procurarão uma saída pelo excesso narcísico, um retorno ao órgão, ao corpo real, no lugar de um investimento simbólico, como alternativa para se lidar com uma excitação, uma angústia, um vazio, devidos à separação do objeto do mundo exterior e, também, à ausência de 
palavras para lidar com uma tal angústia de separação. A autora escreve a esse respeito:

... E é bem uma forma de angústia que aparece quando falta o tóxico, como se o corpo, no lugar de se formar nas cadeias significantes, chamasse a restituição de um órgão que "liga" as excitações. Estas últimas suscitam uma Hilflosigkeit que testemunha um aumento intolerável das tensões. É aliás freqüente como em resposta às formas de vazios (arrombamentos) que "recaídas" intervêm neste tempo da abstinência. O tóxico ressurge como que para restaurar uma proteção face aos acontecimentos ou pensamentos freqüentemente sentidos como ameaçadores, próprios a despertar o terror e o pavor. (...)

mas este modelo do vazio parece representar uma constante clínica quando o uso de tóxicos se transformou numa operação do phármakon.

Como se pode conceber este vazio (arrombamento)? Ele parece adquirir uma forma de inteligibilidade se ele se acha remetido ao "reduplicamento narcísico" que a operação do phármakon organiza. Nenhum desses vazios sobrevêm precisamente, quando se realiza uma tal operação. E é bem muito freqüentemente uma espécie de meio-sono que o phármakon provoca, criando como que um retraimento dos investimentos do mundo exterior. Um tal "reduplicamento narcísico", que tenta "ligar" as excitações, marca o fracasso de uma ligação mais estruturante: de fato, a noção freudiana de vazio implica aqui numa falha da ancoragem do corpo nas cadeias significantes. (pp. 46-47)

Pela passagem acima vê-se que, em Le Poulichet, a "não-substância" que intoxica na “Operação do Phármakon” é excesso narcísico, um reduplicamento do narcisismo a partir da retirada dos investimentos nos objetos do mundo exterior. A autora não faz aqui uma referência direta ao narcisismo "auto-erótico". No entanto, é nele que se é convidado a pensar quando ela situa esta "Operação do Phármakon" enquanto impossibilidade de se fazer um luto completo pela inserção no simbólico. Parece haver uma espécie de luto pela metade, um “meio-sono”, já que, por um lado, tanto a substância química quanto a "Operação do Pharmakon” conseguem realizar uma separação dos objetos do mundo exterior, supostamente uma separação da mãe do primeiro tempo do Édipo, mas, por outro lado, não permitem a completa inserção no mundo simbólico, pois ocorre um retorno ao corpo real. É este retorno que evocaria o narcisismo auto-erótico, o bebê que chupa o polegar 
Tóxico e Adicção Comparados a Paixão e Toxicomania:Etimologia...

quando se separou do seio da mãe, mas, ao mesmo tempo, o repete num lugar real situado numa parte do seu próprio corpo, isto é, seu "dedo-seioda-mãe” que ele então chupa. Este objeto auto-erótico, o “dedo-seio-damãe”, por exemplo, encerraria uma dupla dimensão, ao mesmo tempo "meio-simbólica” e "meio-real”: por um lado, "meio-simbólica”, já que, enquanto "símbolo", re(-a)presenta o seio da mãe; por outro lado, "meioreal”, já que remete ao investimento neste órgão real que é o dedo chupado. O conjunto deste objeto auto-erótico repensado no campo das intoxicações permite que se chegue a um paradoxo em torno da seguinte proposição: “(Há)(s)simbólico” (Há simbólico e também assimbólico) nesta "nãosubstância”, que, apesar do seu estatuto de "não-substância”, possui seu componente real numa parte do corpo investida auto-eroticamente, o que constitui o objeto da intoxicação investido na "Operação do Phármakon”.

Mais adiante em sua obra, sem identificar literalmente o "narcisismo auto-erótico”, é a ele que Le Poulichet se referirá um pouco mais diretamente quando, ao questionar o estatuto da sexualidade tóxica em Freud, dará destaque à masturbação. Como se sabe, a masturbação é para Freud o protótipo das toxicomanias. A esse respeito, Freud (1950/1977) escreve:

... Comecei a compreender que a masturbação é o grande hábito, o "vício primário", e que é somente como sucedâneo e substituto dela que outros vícios álcool, morfina, tabaco, etc. - adquirem existência. (p. 367, ver passagem correspondente na edição francesa: Freud, 1950/1991, pp. 211-212)

Sobre o elo entre o auto-erotismo e a masturbação, Laplanche e Pontalis (1998) esclarecem, a partir da significação de auto-erotismo:

A) Em sentido amplo, característica de um comportamento sexual em que o sujeito obtém a satisfação recorrendo unicamente ao seu próprio corpo, sem objeto exterior: neste sentido, a masturbação é considerada como comportamento autoerótico. (p. 47)

E sobre a sexualidade tóxica em Freud associada às masturbações, no campo, então, do “narcisismo auto-erótico”, Le Poulichet (1987) escreve:

Qual é então o estatuto desta sexualidade tóxica em Freud? (...) 


\section{Victor Eduardo Silva Bento}

Freud afirma que a necessidade sexual é devida à ação de substâncias químicas, semelhante àquela dos estupefacientes. E em 1898 (Em: “A sexualidade na etiologia das neuroses”), especialmente, ele aconselhava para o tratamento da neurastenia uma desabituação dos hábitos masturbatórios (p. 86)

Finalmente, para propor sua idéia da “Operação do Phármakon” como uma autoconservação paradoxal, Le Poulichet escreverá:

Esta operação do phármakon aparece bem como uma tentativa de criação de um fictício “aparelho psíquico" autônomo, que extravia (confunde) todo processo de castração. A autonomia se entende sobretudo aqui como ilusão da condição de um

"Eu” que não estaria assujeitado a uma cadeia temporal de representações. (p. 89)

Pela passagem acima, se é convidado a pensar que a "Operação do Phármakon" traria uma aparência de autonomia e de elaboração da castração, já que, promovendo a separação dos objetos da realidade exterior, geraria uma independência destes, e, simbolicamente, da mãe do primeiro tempo do Édipo. No entanto, tratar-se-ia aqui de uma pseudo-independência, de uma independência ilusória da mãe, já que, havendo fracasso no acesso à dimensão simbólica das representações, a dependência materna seria retomada através do vínculo com o seu objeto substituto, seu equivalente funcional, no campo do "narcisismo auto-erótico" investido em excesso. O paradoxo consistiria então em se destacar a "Operação do Phármakon” como promotora simultaneamente de independência e dependência, elaboração da castração e impedimento radical à mesma elaboração.

Caberia ainda dizer que o sentido passional, presente no "tóxico" e na "toxicomania”, como se viu acima, também confirmará a existência deste sentido paradoxal dos dois termos. Pois a "paixão” também comporta ela própria um sentido paradoxal ao reunir simultaneamente sentidos opostos como cegueira e racionalidade, fraqueza e força etc. A esse respeito, Meyer (1994), ao escrever sobre a história das paixões na filosofia, concluirá:

Desde a Renascença que as paixões fazem parte das observações feitas pelos escritores, moralistas e filósofos sobre o homem. (...)

As paixões servem para caracterizar as relações entre os homens, tanto para o melhor como para o pior. (...) 
Tóxico e Adicção Comparados a Paixão e Toxicomania:Etimologia...

\begin{abstract}
A grande viragem do agostinianismo, que encerrava o homem no pecado, permite integrar as paixões no seio do discurso, tornando-as racionais, apesar de serem paixões. É aí que reside todo o paradoxo das paixões. Elas exprimem uma racionalidade subjacente à nossa cegueira e aos nossos desregramentos, formam uma razão sob o caos das aparências e até da História. (pp. 151-152)
\end{abstract}

Finalmente, para concluir este item, caberia propor uma organização para a relação existente entre estes três termos tão abordados neste item: toxicomania, paixão e narcisismo. Para tal, valeria evocar o estudo de Bento (1996), onde se verá que o autor compara a paixão e a toxicomania a partir de uma analogia funcional, isto é, de uma função psíquica inconsciente semelhante nas duas: o excesso do narcisismo auto-erótico. ${ }^{7}$

\title{
Sobre a etimologia do termo "adicção" e suas relações com a "toxi- comania" e a "paixão"
}

No “Grand Dictionnaire de la Psychologie”, Valleur (1991, p.15) apresenta o termo "adicção" da seguinte maneira: substantivo inglês, relação de dependência alienante, particularmente farmacodependência, "assuétude”, ou toxicomania.

“Assuétude” não é um termo francês da atualidade, não sendo referido, por exemplo, no clássico dicionário de língua francesa do século XX Le Petit Robert (Robert, 1992).

O dicionário francês do "Centre Didro", um centro de documentação e informação sobre o universo da droga e o mundo dos drogados, assim refere este termo:

“Assuétude”:

(01) Escravização à droga, engendrando um estado imperioso com dependência psíquica e freqüentemente física.

(17) Antigo equivalente de “toxicomania”.

7 Para o autor interessado no detalhamento desta discussão, ver Bento (1996). 
Este termo não é mais utilizado hoje. (Le Centre Didro, 1980, p. 16)

Na França, o termo "adicção” é pouco utilizado. Ele não é encontrado em nenhum dos seguintes dicionários clássicos de língua francesa: nem no Robert (1992), no século XX; nem no Littré (s.d.), nem em La Grande Encyclopédie Inventaire Raisonné des Sciences, des Lettres et des Arts (s.d.), e nem no Trésor de la Langue Française (1971), no século XIX; nem no Furetière (1970), no século XVII; e nem no Huguet (s.d.), no século XVI. "Adicção" como termo francês aparecerá apenas no século XVIII, na enciclopédia de Diderot e D’Alembert, onde estes autores apontam a origem etimológica latino-romana e jurídica do termo, como se pode ver na citação a seguir:

ADICÇÃO (...) na lei Romana, é a ação de fazer passar ou de transferir bens a um outro, seja por sentença de uma corte, seja por via de venda àquele que oferece mais. Veja ALIENAÇÃO. (...)

Ele (o termo addiç̧ão) é formado de addico, uma das palavras determinadas ao uso dos juízes Romanos, quando eles permitiam a entrega da coisa ou da pessoa, sobre a qual se havia passado em julgamento.

Eis porque os bens adjudicados desta maneira pelo pretor ao verdadeiro proprietário, eram chamados bona addicta; e os devedores entregues por esta mesma via a seus credores para pagar suas dívidas, se chamavam servi addicti.

Addictio in diem significava a adjudicação de uma coisa a uma pessoa por um certo preço, até que um dia determinado o proprietário ou alguma outra pessoa desse ou oferecesse mais. (Diderot \& D’Alembert, 1751/1988, p. 128)

Neste sentido latino-romano amplo de adicção como "escravização por determinação legal como última forma para pagamento de dívidas”, como "aprisionamento a que se é obrigado para saldar dívida", como "fato de se submeter à dominação de alguém”, não se reencontra o antigo e amplo sentido grego de "paixão como fato de sofrer uma ação", assim como suas implicações semiológicas mais particulares de "paixão como submissão a 
Tóxico e Adicção Comparados a Paixão e Toxicomania:Etimologia...

uma ação exterior sobre o corpo" e de "paixão como escravização",? Não existiria aqui uma analogia funcional " entre a "paixão" e a “adicção”, ambos os termos tomados em sentido amplo?

Nadeau (1982, 1989) propôs que o termo “assuétude” fosse a tradução francesa para o termo inglês "adicção”. Sublinhando o caráter genérico dos dois termos, que englobam o abuso de produtos e certos excessos comportamentais, Nadeau escreverá:

Escolheu-se traduzir o termo addiction por assuétude (Nadeau, 1982). O termo assuétude é uma tradução francesa do termo inglês addiction. (...)

Os trabalhos sobre a assuétude, nós o dissemos, possuem a característica principal de analisar no interior de um mesmo quadro conceitual os fenômenos do abuso de produtos e certos excessos comportamentais. Por abuso de produtos, é preciso entender a sobreconsumação de substâncias psicotrópicas ou alimentares, ou seja: os opiáceos, os sedativos, os hipnóticos, os tranqüilizantes menores, os estimulantes, os alucinógenos, o álcool, a cannabis, o tabaco, a cafeína e a alimentação. Por excessos comportamentais, é preciso entender as dificuldades como os excessos no trabalho, na escuta da televisão, nos esportes, no jogo, ou bem os relacionamentos amorosos, passionais e exclusivos. (Nadeau, 1989, p. 10)

“Assuétude” é igualmente indicado no Petit Robert (Robert, 1992) como sendo a tradução francesa do termo inglês "addiction”. Além disso, este dicionário diz que a palavra "assuétude" veio do latim "assuetudo" ("hábito"), que seu sentido didático remete ao "hábito a uma substância tóxica” e à "toxicomania”.

A crítica que se pode fazer é que esta tradução "assuétude” peca ao colocar a ênfase no hábito em relação à substância tóxica, em detrimento da origem etimológica do termo “adicção”, onde se vê o destaque não dessa

8 Para os detalhes da "Semiologia” do termo "Paixão", ver Bento (1996, item 2.2). Neste outro trabalho procurou-se discutir este sentido antigo e geral, na Antiguidade Grega, de "paixão como fato de sofrer uma ação", em suas implicações semiológicas mais particulares de "paixão como submissão a uma ação exterior sobre o corpo” e de "paixão como escravização”.

9 Para os detalhes da discussão sobre a noção de "analogia funcional”, ver Bento (1996, introdução, item 1). 
substância, mas do entregar-se, do dar-se, do se deixar escravizar, do "s'adonner". Este último verbo pronominal francês, que vem do latim popular "addonare” e remete ao século XII, se refere, no Petit Robert (Robert, 1992), ao fato de "entregar-se com constância a" (uma atividade, uma prática, enfim, a uma paixão). Este dicionário dará, como exemplo: "Ela se entregava passionalmente ao estudo"; "Um indivíduo entregue à bebida”.

Assim, pode-se propor "s'adonner" como sendo a melhor tradução francesa para "addiction” em inglês, mais precisamente para esta dimensão subjetiva e passional presente na idéia de "escravização por determinação legal como última forma para pagamento de dívidas" que se extrai da "adicção” latino-romana. Ou ainda melhor, pode-se propor que não se realize nenhuma tradução, mas sim, a simples retomada da antiga expressão francesa "addiction” que, como foi assinalado acima, é referida apenas no dicionário clássico de língua francesa do século XVIII por Diderot e D’Alembert.

Na literatura francesa pode-se encontrar autores que valorizam esta dimensão mais ampla do termo "addiction” em sua origem etimológica latino-romana. Bergeret (1981, p. 16), por exemplo, mesmo sem fazer referência ao verbo "s’adonner" como tradução francesa para “addiction”, dirá, no entanto, que este último termo corresponde a uma acepção francesa antiga retirada do latim para designar um "aprisionamento (por determinação legal ao qual se obriga um devedor) como último recurso contra o não pagamento de uma dívida”. Este autor escreverá a esse respeito:

Os autores anglo-saxões possuem o hábito de empregar o termo "addiction” para dar conta de um comportamento de dependência designado em geral em francês sob o termo de 'toxicomania'.

Parece que uma tal escolha seja suficientemente feliz porque ela corresponde a um sentido mais amplo que aquele ao qual nós temos o hábito de recorrer para designar um comportamento de dependência. Com efeito, ‘toxicomania' coloca a ênfase na importância do produto tóxico no comportamento enquanto que 'addiction' retoma uma denominação francesa antigamente utilizada para designar um aprisionamento infligido aos devedores que não podiam chegar a honrar de outra forma seus credores. (Bergeret, 1981, p. 9) 
Tóxico e Adicção Comparados a Paixão e Toxicomania:Etimologia...

(...) é possível tomar o substantivo "addiction" (na sua primeira proposição etimológica) tanto em sua significação anglo-saxônica de vinculação ao objeto quanto em sua acepção francesa antiga tirada do latim de aprisionamento (por determinação legal ao qual se obriga um devedor) como último recurso contra o não pagamento de uma dívida. (p. 16)

\section{Conclusão}

Este trabalho discutiu a etimologia dos termos "tóxico", prefixo de “tóxico-mania”, e “adicção”, a partir de um ponto de vista psicanalítico. Chegou-se às seguintes conclusões: 1) embora surgindo em tempos bem distintos, "tóxico" e "toxicomania" aparecem associados à mesma idéia de uma "substância química" que ataca o organismo; 2) os sentidos etimológicos originários de "paixão" e "tóxico” parecem se aproximar: "paixão como fato de sofrer passivamente uma ação prejudicial”, em Aristóteles e no sofrimento de Cristo, lembra o "tóxico" utilizado na ponta das flechas pelos povos bárbaros anteriormente ao século II nos ataques de guerra, a idéia de um sofrimento passivo, prejudicial para aquele que é atacado pela flecha envenenada; 3) o termo "toxicomania” também se aproxima da paixão em seu sentido etimológico originário, pois nasce no campo médico, no fim do século XIX, associado aos sentidos de "degenerescência”, "imoralidade” e "paixão"; 4) o sentido de paradoxo foi encontrado nos termos "tóxico”, "toxicomania”, e "paixão”; e 5) na "adicção” que surge nos tempos do império Romano "como escravização por determinação legal como última forma para pagamento de dívidas”, como "aprisionamento a que se é obrigado para saldar dívida”, como “fato de se submeter a dominação de alguém”, se reencontrou o antigo e amplo sentido grego de "paixão como fato de sofrer uma ação”, assim como suas implicações semiológicas mais particulares de "paixão como submissão a uma ação exterior sobre o corpo” e de "paixão como escravização". 


\title{
Victor Eduardo Silva Bento
}

Bento, V. E. S. (2006). Toxin and addiction compared to passion and toxicomania: etymology and psychoanalysis. Psicologia USP, 17(1), 181-206.

\begin{abstract}
From a psychoanalytical point of view, the etymology of "toxin" and "addiction" was compared to "passion" and "toxicomania" etymology. We concluded: $1^{\text {st }}$ " "toxin" and "toxicomania” mean a chemical substance which attacks the organism; $2^{\text {nd }}$ - "Passion" and "toxin" original etymological meanings are similar: "passion like passive physical pain”, in Aristoteles and Christ, reminds the "toxin" in the dart used by the barbarians before the 2 A.D. in the war attack, the passive physical suffering by someone attacked; $3^{\text {rd }}$ - "toxicomania" comes from the medical domain, at the end of the $19^{\text {th }}$ century, meaning "degeneration", "immorality" and "passion"; $4^{\text {th }}$ - We found the meaning of paradox in "toxin”, "toxicomania" and "passion"; and $5^{\text {th }}$ - In the "addiction" coming from the Roman empire as "enslavement by legal determination to pay for some debt" we found the old Greek meaning of "passion as enslavement, passive suffering, submission to an action from the outside”.
\end{abstract}

Index terms: Toxin. Addiction. Passion. Psychoanalysis. Etymology

Bento, V. E. S. (2006). Toxique et addiction comparés à passion et toxicomanie:étymologie et psychanalyse. Psicologia USP, 17(1), 181206.

Resumé: À partir d'une optique psychanalytique, l'étymologie de "toxique” et "addiction" est comparée à celle de "passion" et "toxicomanie”. Les conclusions sont: $1^{\circ}$ - "toxique” et "toxicomanie" renvoient à la "substance chimique" qui atteint l'organisme; $2^{\circ}$ - Les sens etymologiques originaires de "passion” et "toxique” s'assimilent: "passion comme fait de subir une action nuisible”, "souffrance passive” chez Aristote et Jésus-Christ semble le "toxique" à la pointe des flèches empoisonnées utilisées par les barbares avant le 2e siècle aux temps de guerre, la souffrance passive, nuisible pour celui qui est atteint par ces flèches; $3^{\circ}$ - La "toxicomanie" se rapproche de la passion puisqu'elle naît dans le domaine médical, à la fin du XIXe siècle, définiée comme “dégénérescence”, “amoralité” et "passion”; $4^{0}$ - Le sens de paradoxe se trouve dans "toxique”, "toxicomanie” et "passion”; et 50- On retrouve le sens d'“addiction” qui apparaît à l'empire romain comme "esclavage en 
Tóxico e Adicção Comparados a Paixão e Toxicomania:Etimologia...

paiement de dettes" dans l'ancien sens grec de "passion comme esclavage, souffrance passive et soumission à une action extérieure sur le corps".

Mots-clés: Toxique. Addiction. Passion. Psychanalyse. Étymologie.

\section{Referências}

Aristote. (1991). Métaphysique (J. Tricot, trad., T. 1 - Livres A-Z). Paris: Librairie Philosophique J. Vrin.

Aristóteles. (2002). Metafísica (M. Perine, trad., Vol. 2). São Paulo: Loyola.

Bento, V. E. S. (1993). Tóxico, droga, toxicomania e adicção: uma introdução à etimologia segundo uma ótica psicanalítica. Jornal Brasileiro de Psiquiatria, 42(7), 373-80.

Bento, V. E. S. (1994a). Leonardo da Vinci e uma lembrança da sua infância: considerações sobre o narcisismo em Freud e sobre a paixão amorosa "tóxica" a partir de Freud. Temas: Teoria e Prática do Psiquiatra, 24(47), 94-113.

Bento, V. E. S. (1994b). Três ensaios sobre a teoria da sexualidade: considerações sobre o conceito de narcisismo em Freud (1905) e sobre a paixão amorosa "tóxica" a partir de Freud. Revista ABP-APAL, 16(4), 154-164.

Bento, V. E. S. (1995). O presidente Schreber, um caso de paranóia: considerações sobre o narcisismo em Freud (1911) e sobre a paixão amorosa "tóxica" a partir de Freud. Informação Psiquiátrica, 14(1), 27-35.

Bento, V. E. S. (1996). La passion amoureuse "toxique": une approche psychanalytique à partir de la sémiologie et du narcissisme chez Freud. Thèse de Doctorat (Psychopathologie Fondamentale et Psychanalyse), Université Paris 7, Paris, France.

Bento, V. E. S. (1998). O narcisismo em Freud e paixão “tóxica” a partir de Freud. Psicologia em Estudo, 3(2), 1-37.

Bento, V. E. S. (1999). Pour introduire une "sémiologie psychanalytique" de la notion de "toxicomanie" dans l'approche médicale. Interventions: Revue de l'ANIT Association Nationale des Intervenants en Toxicomanie, 68, 16-22.

Bergeret, J. (1981). Aspects économiques du comportement d'addiction. In M. Bandelier (Org.), Le psychanalyste à l'écoute du toxicomane (pp. 9-25). Paris: Dunod. 


\section{Victor Eduardo Silva Bento}

Chassaing, J. L., Balbure, B., Dufour, A., Farges, F., \& Petit, P. (Coords.). (1998). Écrits psychanalytiques classiques sur les toxicomanies. Paris: Association Freudienne Internationale.

De Félice, P. (1936). Poisons sacrés, ivresses divines: essai sur quelques formes inférieures de la mystique. Paris: Albin Michel.

De Mijolla, A., \& Shentoub, S. A. (1981). Pour une psychanalyse de l'alcoolisme. Paris: Payot. (Trabalho original publicado em 1973)

Delrieu, A. (1988). L'inconsistance de la toxicomanie. Analytica. Cahiers de Recherche du Champ Freudien, (53).

Derrida, J. (1995). La pharmacie de Platon. In Platon \& J. Derrida, Phèdre suivi de La pharmacie de Platon (pp. 255-403). Paris: GF-Flammarion. (Trabalho original publicado em 1968)

Derrida, J. (1997). A farmácia de Platão (2a ed.). São Paulo: Iluminuras. (Trabalho original publicado em 1968)

Diderot, D., \& D’Alembert, J. L. (1988). Encyclopédie ou dictionnaire raisonné des sciences des arts et des métiers (Vol. 1). Stuttgart - Bad Cannstatt: Friedrich Frommann Verlag (Günther Holzboog). (Trabalho original publicado em 1751)

Diderot, D., \& D’Alembert, J. L. (1967). Encyclopédie ou dictionnaire raisonné des sciences des arts et des métiers (Vol. 16). Stuttgart - Bad Cannstatt: Friedrich Frommann Verlag (Günther Holzboog). (Trabalho original publicado em 1765)

Ferbos, C., \& Magoudi, A. (1986). Approche psychanalytique des toxicomanes. Paris: PUF.

Freud, S. (1974). Sobre o narcisismo: uma introdução. In S. Freud, Edição standard brasileira das obras psicológicas completas de Sigmund Freud (J. Salomão, trad., Vol. 14, pp. 83-119). Rio de Janeiro: Imago. (Trabalho original publicado em 1914)

Freud, S. (1977). Carta 79. Extratos dos documentos dirigidos a Fliess (1892-1899). In S. Freud, Edição standard brasileira das obras psicológicas completas de Sigmund Freud. (J. Salomão, trad., Vol. 1, pp. 367-369). Rio de Janeiro: Imago. (Trabalho original publicado em 1950)

Freud, S. (1991). Lettre no. 79 à Wilhelm Fliess du 22-12-97. In S. Freud, La naissance de la psychanalyse (A. Berman, trad., 6a ed., pp. 211-213). Paris: PUF. (Trabalho original publicado em 1950)

Furetière, A. (1970) Dictionnaire universel contenant généralement tous les mots français tant vieux que modernes et les termes de toutes les sciences et des arts ( $\mathrm{T}$. 1). Genève: Slatkine Reprints. 
Tóxico e Adicção Comparados a Paixão e Toxicomania:Etimologia...

Huguet, E. (s.d.). Dictionnaire de la langue française du seizième siècle (T. 1). Paris: Didier.

La Grande Encyclopédie Inventaire Raisonné des Sciences, des Lettres et des Arts. (s.d.). (T. 1). Paris: H. Lamirault \& Cio.

Lalande, A. (1993). Vocabulaire technique et critique de la philosophie (3e ed.). Paris: Quadrige \& PUF. (Trabalho original publicado em 1926)

Lalande, A. (1996). Vocabulário técnico e crítico da filosofia (2a ed.). São Paulo: Martins Fontes. (Trabalho original publicado em 1926)

Laplanche, J., \& Pontalis, J.-B. (1998). Vocabulário da psicanálise (2a ed.). São Paulo: Martins Fontes.

Le Centre Didro. (1980). Dico Didro (2e ed.). Paris: Centre Didro.

Le Poulichet, S. (1987). Toxicomanies et psychanalyse. Les narcoses du désir. Paris: PUF.

Levinstein, E. (1878). La morphiomanie. Paris: Masson.

Littré, É. (s.d.). Dictionnaire de la langue française (T. 1). France: Gallimard \& Hachette.

Littré, É. (1967). Dictionnaire de la langue française (T. 7). France: Gallimard \& Hachette.

Meyer, M. (1994). O filósofo e as paixões. Esboço de uma história da natureza humana. Porto, Portugal: Asa.

Nadeau, L. (1982). Avant-Propos. In S. Peele, L'expérience de l'assuétude. Montréal: Faculte de l'éducation permanente, Université de Montréal.

Nadeau, L. (1989). Une introduction à l'approche nord-américaine. Nervure, 8(2), 1014.

Robert, P. (1992). Le Petit Robert 1: dictionnaire alphabétique et analogique de la langue française. Paris: Le Robert.

Robert, P., Rey, A., Rey-Debove, J., Cottez, H., Lafite, S., Léotard, L. et al. (1988). Dictionnaire de noms propres. In P. Robert, A. Rey, J. Rey-Debove, H. Cottez, S. Lafite, L. Léotard et al., Le Micro-Robert: langue française plus noms propres chronologie - cartes (2e ed., pp.1-306). Paris: Dictionnaires Le Robert.

Saussure, F. de (1995a). Cours de linguistique générale (T. de Mauro, Édition critique). Paris: Payot \& Rivages. (Trabalho original publicado em 1916)

Saussure, F. de (1995b). Curso de lingüística geral (A. Cheline, J. P. Paes, \& I. Blikstein, trads.). São Paulo: Cultrix. (Trabalho original publicado em 1916) 


\section{Victor Eduardo Silva Bento}

Trésor de la Langue Française. (1971). Dictionnaire de langue du XIXe. et du XXe. siècle (1789 / 1960) (T. 1). Paris: Centre National de la Recherche Scientifique.

Valleur, M. (1991). Addiction. In Grand dictionnaire de la psychologie (p. 15). Paris: Larousse.

Recebido em: 24.02.2006

Aceito em: 10.04.2006 